\title{
Meaning Holism and De Re Ascription
}

\section{Daniel Whiting}

The definitive version of this article is published in Canadian Journal of Philosophy (2008) 38: 575-599.

\section{Introduction}

According to inferential role semantics (IRS), for an expression to have a particular meaning or express a certain concept is for subjects to be disposed to make, or to treat as proper, certain inferential transitions involving that expression. ${ }^{1}$ Such a theory of meaning is holistic, since according to it the meaning or concept any given expression possesses or expresses depends on the inferential relations it stands in to other expressions.

It is widely recognised that this holism leads to two prima facie problems for IRS.

First, since no two speakers share the same beliefs, they will inevitably be disposed to make, or treat as correct, different inferential transitions involving an expression. Hence, according to IRS, the same word in different mouths will possess a different meaning and be understood in different ways. It seems to follow that communication is impossible. Second, and relatedly, since a particular speaker's beliefs are constantly changing, at different times she will inevitably be disposed to make, or treat as correct, different inferential transitions involving an expression. Hence, according to IRS, the same word in the same mouth will possess a different meaning and be 
understood differently at different times. It seems to follow that constancy of meaning is impossible. In this paper, I shall focus only on the former problem of communication, although much of what I say will bear on the latter problem of constancy.

Proponents and detractors of IRS alike typically hold that the way to avoid this is to introduce a distinction in kind between those inferential transitions that are determinative of the meaning of an expression and those that are not, i.e. an analytic/synthetic distinction (see Boghossian, 1993; 1994; 1997; Fodor and Lepore, 1991; 1992; Horwich, 1992; 1998; 2005, 38-9; Lepore, 1994; Peacocke, 1992). ${ }^{2}$ Each party differs only on the issue of whether such a distinction can or should be drawn.

In contrast, Brandom seeks to resolve the communication problem facing IRS without drawing an analytic/synthetic distinction. In his own words, Brandom refuses to adopt such an 'inegalitarian attitude toward the different inferences a concept is involved in' (MIE, 634; cf. 484, 587). His egalitarian and novel alternative, which I shall examine in this paper, is to appeal to the nature of de re ascriptions. ${ }^{3}$

In what follows, I shall take for granted, with Brandom and those authors referenced above, that the communication problem poses a genuine difficulty for IRS and so calls for some kind of response (cp. Block, 1995; Harman, 1993). I shall begin by outlining the details of Brandom's particular version of IRS and register his recognition of the communication problem $(\S 2)$. Next, I shall outline the apparatus he introduces in order to resolve that problem, namely that of de re ascription (§3). Having done so, I shall argue that Brandom's alternative to the traditional appeal to analyticity fails in 
several respects to provide a genuine explanation of shareable meaning and mutual understanding $(\S 4)$.

In a number of places, Brandom suggests that the mechanism of de re ascription introduces an externalism, according to which the meaning of an expression or the concept it expresses is determined by the linguistic practitioners' physical environment. This, I shall claim, is either in tension with IRS or fails to provide a genuine account of shared meaning $(\S 5)$.

One might think that informing my objections to Brandom's appeal to de re ascription is a suspect and demanding view of communication, one that can and should be challenged. After sketching that view on behalf of my opponent, I shall show that, irrespective of whether it is indeed suspect, the criticisms can be motivated independently of it (§6). Specifically, they apply equally by the standards of Brandom's favoured model of communication.

In closing, I recommend that one sympathetic to IRS - and in particular to the version that Brandom develops - accept the traditional response to the communication problem, namely that of drawing a distinction in kind between those inferential transitions that are determinative of meaning and those that are not (§7). Since at least Quine's ‘Two Dogmas of Empiricism' (1951), many consider such an analytic/synthetic distinction to be obsolete. Although I am confident that a defensible notion of analyticity can be provided, and thus that IRS can avoid this particular problem, I shall leave that task for another occasion. ${ }^{4}$ 


\section{Meaning holism and the communication problem}

Brandom recommends a version of IRS, according to which the content of a performance, and derivatively the meaning of an expression, ${ }^{5}$ is to be understood to consist in its being subject to inferential proprieties. This 'semantically primitive notion of material proprieties of inference' is in turn accounted for by a 'normative pragmatics' (MIE, 623). ${ }^{6}$ Ultimately, Brandom claims, for an assertion to express a given content, and so the sentence uttered to have a certain meaning, is for practitioners to treat it appropriately in practice as entitled or otherwise, and as committing practitioners to the propriety of further performances as a result. If one were to enumerate all the commitments and entitlements the utterance of any sentence involves, one would thereby capture what proposition is expressed, and so the meaning of the sentence used. The ability to understand a language ('scorekeeping') is the practical capacity to keep track of these commitments and entitlements (the 'score') (see MIE, chs. 2-3). ${ }^{7}$

Brandom notes that such a story is committed to holism about meaning (AR, 15-6; MIE, 89-91). If contents are individuated by the inferential relations they stand in to other contents or, in scorekeeping terms, if the significance of a performance is taken to consist in its relation to other performances, then it follows that there cannot be one content or significance without others. I consider this innocuous. However, the degree of holism that Brandom is prepared to countenance is greater (and more problematic) than this. Brandom commits himself to a global holism, according to which the content of a performance (or meaning of an expression) is determined by all the inferential relations it stands in. 
In a number of places, Brandom notes a potential difficulty for IRS that stems from global holism, namely the communication problem. He observes that such holism 'seems to threaten the intelligibility of mutual understanding and so of successful communication' (MIE, 587-8). ${ }^{8}$ The problem occurs because what else a commitment with a particular content commits one to $[\ldots]$ depends on its deontic context, on what concomitant commitments are available as auxiliary hypotheses or collateral premises. (MIE, 504) ${ }^{9}$

In view of our different beliefs, or in scorekeeping terms our different practical attitudes, the commitments I take the utterance of a given expression to involve will differ from those you take it to involve. So, if the semantic content expressed by an utterance (or derivatively the meaning of the tokened expression) is to be explained in terms of the normative status that it possesses, it would seem that that content (or meaning) differs according to one's own commitments. Brandom summarises the problem as follows:

We each embody different perceptual and practical perspectives and so will never have exactly the same commitments [...] As long as there are differences in the collateral set of commitments with respect to which the content of the claim expressed by a sentence needs to be assessed, the sentence in one mouth means something different from what that same sentence means in another mouth. (MIE, 509-10; cf. 475, 587) ${ }^{10}$

This appears to result in a kind of quasi-Cartesian privacy about meaning. If 'inferential significance is not preserved in communication' (MIE, 480), then mutual understanding is not possible. Imagine, for example, that Sophie utters:

(1) The car is parked in the garage. 
Given our different beliefs, Sophie takes the utterance of such words to have a very different inferential significance than I do. She would not infer to, 'The vehicle that ran over the cat is parked in the garage'. It follows, given IRS and global holism, that we understand the words and what is expressed by their use differently. Hence, communication is impossible.

One might wonder whether Brandom's IRS requires that shared understanding be possible. Perhaps communication requires only sufficiently similar understanding. The problem with a suggestion of this kind, as Fodor and Lepore point out (1992, 1722 ), is that it simply assumes shared concepts (or mutual understanding of the corresponding expressions). Consider how one might ascertain similarity. Presumably one would need to enumerate the various inferences that any two speakers are prepared to treat as proper. Their understanding is similar just in so far as they are prepared to make a sufficient number of the same inferences. But what is to count as the same inference? Surely those that contain identical concepts. Clearly, then, this strategy presupposes rather than explains the fact that speakers possess identical concepts (or have the same understanding of the corresponding expressions).

A seemingly obvious solution to the communication problem would be to draw a line between those inferential relations that are determinative of an expression's meaning, or correlatively essential to understanding what is expressed by its utterance, and those that are not, traditionally labelled the analytic/synthetic distinction. But, as quoted above, Brandom rejects this strategy (for familiar Quinean reasons). In the next section, I shall outline his alternative explanation of the possibility of 
communication. (No doubt there are other possible strategies for resolving the difficulty, but the focus of this paper is Brandom's proposal.)

\section{De dicto and de re ascription}

Brandom aims to show that, on his theory, it is the specification or expression of content that is perspectival, not the content itself. To deal with the difficulties global holism raises, Brandom appeals to the role of ascriptional locutions, such as 'claims',

understood in the terms of his version of IRS. ${ }^{11}$ I shall outline how that appeal is supposed to meet those problems. (This section is wholly exegetical; critical assessment is reserved until later.)

Ascriptional locutions are used to specify the content of another's claim. For example, given Sophie's utterance of (1), I might utter:

(2) Sophie claims that the car is parked in the garage.

In the vocabulary Brandom employs, such an ascription makes explicit one's own practical attitude of attributing a normative status. That is, the content one ascribes is supposed to capture the normative significance one takes the utterance to have. In making an ascription, one attributes a commitment to the target while simultaneously undertaking a different commitment oneself, namely to a claim about what someone else claims.

It seems, however, that there is a difficulty for the use of such locutions, resulting from the holism outlined above. Expressions occurring within an ascription must play a dual role; they must express both the attributed commitments and the commitments 
thereby undertaken by the ascriber. Hence the familiar problem of differences in inferential profiles arises in the special case of ascribing claims:

the occurrence of an expression [within an ascription] might have one inferential significance if evaluated with respect to the collateral commitments of the one to whom the commitment is attributed, and might have quite another if evaluated with respect to the collateral commitments of the one who undertakes the ascriptional commitment. (MIE, 504) $)^{12}$

It appears, then, that any given speaker will be unable to make a successful ascription. Consider again (2). Sophie takes the utterance of such words to have a very different inferential significance than I do. Unlike me, she does not believe that the vehicle that ran over the cat is parked in the garage. So I have not specified what she claims as she understands it. But I cannot specify her claim as she sees it, since my perspective differs from Sophie's. It follows, given IRS and global holism, that mutual comprehension is impossible.

The problem facing explicit ascriptions is a vivid case of that facing attributions of semantic content generally. Note, however, that an ascription of the above sort is of the de dicto form. What is distinctive of the de dicto style of ascription, according to Brandom, is that the ascriber [...] is committed to the target being prepared to acknowledge the attributed commitment in essentially the terms specified - that is, to endorse the dictum. (AR, 175; cf. MIE, 500-8) $)^{13}$

Brandom's proposal to the problem of communication is to look not to de dicto but to de re ascriptions. 
In order to make a successful ascription, Brandom suggests, the ascriber must be able to substitute the target's words for terms that in her mouth express the same claim:

if you want to understand what I say, you have to be able to associate with it a sentence that in your mouth expresses the same claim as the sentence uttered in mine. $(\mathrm{MIE}, 509-10)^{14}$

This capacity to substitute expressions with the same inferential relations allows one 'to accommodate differences in discursive perspective, to navigate across them' (MIE p.588). Of course, substitution involves specifying the content in a way that the target of the ascription might not be prepared or in a position to acknowledge. For example, Sophie would not assent to:

(3) Sophie claims that the vehicle that ran over the cat is parked in the garage.

It is this difference in perspective that is marked by the use of de re locutions, which ascribe commitments one takes a target to have without committing oneself to the target acknowledging the commitments so specified. For example:

(4) Sophie claims, of the vehicle that ran over the cat, that it is parked in the garage.

I am thus (supposedly) able to specify her claim in my own terms, with no suggestion that she sees it the same way:

The part of the content specification that appears within the scope of the de re 'of' clause includes what, according to the ascriber of the commitment but not necessarily according to the one to whom it is ascribed, is acknowledged as an expression of what the target of the ascription is committed to. (MIE, 505-6)

So, although the inferential significance of an expression varies according to one's doxastic perspective, one can nonetheless ascribe a claim to another by distinguishing 
that part of the ascription that the target would acknowledge as an expression of her commitments and that part that the target is committed to irrespective of her attitudes. ${ }^{15}$ The latter corresponds to the part of the specification that draws on the ascriber's idiosyncratic commitments, and the former to the part that restricts itself to shared commitments:

Where the specification of the content depends only on auxiliary premises that $[\ldots]$ the target of the ascription acknowledges being committed to, it is put in de dicto position $[\ldots]$ Where the specification of the content depends on auxiliary premises that the ascriber endorses, but the target of the ascription may not, it is put in de re position. (MIE, 506; cf. AR, 177-8)

Mutual understanding, Brandom proposes, depends on this ability to navigate between one's own perspective and that of one's interlocutor, to explicitly specify or implicitly attribute commitment to contents de re. As he unequivocally states, 'what is expressed by de re specification of the contents of the beliefs of others is crucial to communication' (AR, 180, my underlining). ${ }^{16}$

This appeal to de re ascriptions is intended to meet the communication problem that seems to afflict IRS due to global holism. Brandom is, however, far from clear as to how exactly. What follows is an attempt at reconstruction. Since the apparatus of substitution and de re ascriptions make the shared subject-matter of the discourse explicit - by specifying what is being talked about, rather than how it is talked about (MIE, 502-3) - then it (supposedly) secures or anchors communication across perspectives.

Furthermore, insofar as the apparatus of substitution enables one to specify the significance of another's claim, it shows that one can (in principle) grasp that 
significance. And there will be a practical attitude - one of implicitly attributing content - underlying the explicit use of ascriptional locutions. Thus, Brandom contends, genuine understanding of another's performance (and so words) is possible. In this way, one purportedly arrives at a conception of non-perspectival content, and so of meaning. If understanding is shareable, presumably that which is understood is shareable. Although the specification of the content differs from the target's own, it is nonetheless 'the very same claim'. Its content consists, not in the inferential significance any given interlocutor attaches to the expression, but 'in the systematic relations among the various pragmatic significances'; it is a kind of point on the 'coordinated system of scorekeeping perspectives' (MIE, 590-1).

It is important to note that, for Brandom, de re ascriptions mark a distinction between what a performer acknowledges being committed to and what the ascriber considers her to be actually, as a matter of fact, committed to (irrespective of her attitudes) (MIE, 596-7). So, it is the objective proprieties, what a given performance really commits a practitioner to as opposed to what she takes herself to be, a distinction built into scorekeeping, that confers an objective content on a performance and so a shareable meaning on the corresponding expressions (MIE, 631). This, Brandom states, amounts to a semantic externalism according to which 'what we mean depends on how things actually are, whether we know how they are or not' (MIE, 647). Of course, an ability to understand what is expressed, and to intentionally produce sentences with the relevant meaning, requires one be a scorekeeping practitioner. But what is thereby expressed is determined by the non-linguistic environment, as emerges from the differing perspectives scorekeepers have on the significance of their words. 
In this way, Brandom's scorekeeping account of de re ascriptions, and the corresponding implicit practical attitude, is intended to resolve the problems raised by the global holism that he countenances. Social interaction, a feature of scorekeeping practice, supposedly provides the resources for a conception of mutual understanding, and thereby of communicable content or meaning.

\section{$4 \quad$ Criticisms of Brandom's apparatus}

In this section, I shall question whether Brandom's response to the communication problem facing IRS as a result global holism - i.e. his appeal to the mechanism made explicit by de re locutions - is successful. ${ }^{17}$ There are, I shall argue, a number of problems that demonstrate, either cumulatively or individually, that it is not. ${ }^{18}$

\subsection{Substitution}

On Brandom's account, de re ascriptions involve substitution. An example he offers is that of replacing a Zoroastrian's use of the expression 'the seventh god', in an utterance of 'The seventh god has risen', with the expression 'the sun'. Such a substitution would supposedly enable one to place her remark in an inferential context.

First, however, the ability to so substitute the expression surely presupposes that one antecendently understands what the Zoroastrian is saying, or what her words mean; otherwise it is not clear how one could determine the appropriate substitution. That is to say, according to Brandom, genuine understanding of another's claim, despite divergent beliefs, is possible because one can ascribe or attribute a claim from a 
perspective external to the subject's. This is done via substitution. From oratio recta, or direct quotation, one supposedly moves to oratio obliqua, or indirect speech, in the de re style by replacing a speaker's words with one's own and using them to specify her claim (or commitments). However, surely what determines the correct substitution, and hence the correct de re ascription, is what the subject is saying, or what her words mean. Substitution depends on prior mutual understanding, and therefore cannot explain it.

If substitution does not require an independent grasp of what is said, it requires identifying a reference-fixing belief or claim concerning the target. In Sophie's case, this would be something like, 'The car is the blue vehicle with a rusty door'. But any such claim itself stands in a different inferential context for Sophie than the one I take it to stand in, and so the problem of mutual understanding is only pushed back a stage and a vicious regress looms.

Brandom might try and avoid these problems by denying that the de dicto characterisation is cognitively or epistemologically primary, i.e. not the result of an inference but the object of immediate response (although his talk of substitution and navigation clearly suggests it is). However the onus is then on Brandom to explain how the de re conception of what is said can be immediately and non-inferentially accessible, or available in advance of the de dicto (i.e. how one can get to the res without passing through the dictum).

\subsection{Anaphora}


One might complain that I have so far neglected Brandom's appeal to anaphora, which simply side-steps the above objections. Brandom clearly states that 'Interpersonal anaphora plays an important role in securing the possibility of communication' (MIE, 474). However, while it is true that anaphora plays a central part in Brandom's account of de re ascription and has so far been ignored, attending to it only reveals the inadequacies in that account as a solution to the problem of communication.

In the terms of Brandom's IRS, anaphora is 'the inheritance by one tokening [of an expression] from another of the structure that determines which substitutional commitments are relevant to its semantic assessment' (MIE, 473). For example, if Beryl utters 'Jones lied in court', I might respond 'He sounds untrustworthy'. Beryl and I can take both utterances to be about the same individual, even if I know nothing else about that individual, insofar as we treat my utterance of 'he' to be anaphorically dependent on Beryl's utterance of 'Jones'. In virtue of being so dependent, my utterance of 'he' inherits the inferential substitution commitments to which 'Jones' is subject.

Crucially, an anaphorically dependent expression is simply stipulated to be subject to the same proprieties of inferential substitution as its antecedent, and hence a speaker does not need to 'work out' what the correct substitution is (MIE, 486). Thus, if two uses of an expression can be anaphorically linked (in virtue of the attitudes of speakers) then the mechanism of substitution does not suffer from the above difficulties. 
Granting that anaphoric links can be established in this way, the important question is whether this affords a genuine explanation of communication, of one speaker understanding what is said by another speaker. Accordingly, consider Brandom's talk of anaphora enabling the 'inheritance' of inferential substitution commitments. If 'to inherit' means to come to grasp the very same inferential substitution commitments governing an expression as those grasped by one's interlocutor, anaphora does not really allow one to inherit anything at all in this sense. As Brandom himself remarks: the substitutional commitments to be inherited anaphorically by one token from another are assessed by the scorekeeper who attributes the anaphoric commitment. (MIE, 487)

Anaphora alone does not enable me to know what expressions Beryl, rather than myself, would treat as intersubstitutable for 'Jones', or Sophie for 'the car', or the Zoroastrian for 'the seventh god'. Hence, it does not enable me to know what each person is saying, what proposition her utterance expresses. Anaphora might link inferential profiles in the sense of merely associating them, but not in the sense of permitting the sharing or accessing of them. Thus, although it provides a means of substitution that does not presuppose antecedent grasp of meaning, precisely for that reason anaphora, as analysed in the terms of Brandom's IRS, does not make possible communication.

\subsection{The de dicto component}

Even if one grants the intelligibility and success of the substitution strategy, it is still the case that de re ascriptions involve a de dicto component. Consider again:

(4) Sophie claims, of the vehicle that ran over the cat, that it is parked in the garage. 
Given my different perspective, I take 'parked' and 'garage' - which fall within the scope of the de dicto locution - to stand in different inferential contexts than Sophie. She would not infer, for example, from 'That is the garage' to 'That is where the bicycle was stolen'. Hence, there is not really any part of the ascription that both parties can grasp as a specification of the original claim.

Note that, for Brandom, the de dicto specification is restricted to what, according to the ascriber, the target would acknowledge as an expression of her claim. But this is clearly not, by the lights of global holism, a sufficient condition for successful ascription. Even if Sophie, having uttered '...is parked in the garage', assents to the specification contained in the that-clause of (4), the expressions therein nonetheless have a different inferential significance for her than for me. Hence, despite appearances, mutual assent is not a criterion of mutual comprehension.

So it seems that the issue of how the claim is ascribed is not to the point; it is rather what else a subject is committed to. Brandom's focus on what terms are used to express commitments elides the problem of mutual understanding rather than addresses it. But even if one considers the matter only in terms of attributions that distinguish between those commitments, however they are specified, that the target takes herself to have and those that the ascriber takes her as a matter of fact to undertake, equivalent difficulties remain. The problem is simply that, given global holism, there are no commitments that I could attribute and that my interlocutor considers herself to have, since commitments are always inferentially articulated and our inferential profiles always differ. 
It appears that in order properly to avoid the problems global holism raises for IRS, the relevant attribution would have to be wholly de re. Thus, for Brandom, a felicitous ascription of Sophie's claim would be:

(5) Sophie claims, of the vehicle that ran over the cat parked in the garage, that.

First, however, this is hardly grammatical. Second, in the absence of anything expressed by a that-clause, one loses any sense in which a claim is being ascribed.

One is left with a mere demonstration. As a general model of communication, of how speakers interpret one another's words, this ought to be unpalatable enough to make one reconsider the steps that led to it. But, even if one were prepared to bite the bullet, the model fails. ${ }^{19}$

Presumably one would have to hold that, in an ascription such as (5), the second 'that' is functioning as a demonstrative, which picks out the car's being parked in the garage. On this account, the utterance as a whole claims of a demonstrated state of affairs that the target is committed to its obtaining. However, this could only work for true claims, or rather for claims the ascriber takes to be true. If I do not believe, for example, that the car is in the garage, I could not take myself to be demonstrating it. Perhaps one could avoid this problem by ascribing the claim as follows:

(6) Sophie claims, of the vehicle that ran over the cat and of being parked and of the garage, that.

However, one has now lost the 'unity' of the content ascribed. In order for a genuine claim to be ascribed, one needs somehow to 'order' the parts. Doing so requires something to follow the 'that', but of course if something were added then the ascription would no longer be wholly de re. 
Moreover, the significance of a tokened demonstrative too depends on one's doxastic perspective, on what inferential substitutional commitments involving that expression one considers proper. Therefore, insofar as different practitioners will take the same tokening to involve different commitments, their understanding of it will differ. For example, Sophie would not infer from 'That [car] is dented' to 'The vehicle that ran over the cat is dented'. Even if one restricts the attribution to a mere demonstration, then, mutual understanding of a claim is not possible, so long as global holism is in place. $^{20}$

\subsection{Interpersonal significance}

Even if one ignores the above problems with the account of de re ascriptions, it remains the case that when a practitioner makes such ascriptions (or the corresponding implicit attribution) the perspectivism that Brandom's holism enforces remains in place. Under substitution, the ascriber continues to take the specification to have a very different inferential significance than the target. Thus, given IRS, it follows that they understand it differently. In that case, Brandom must concede that no content is shared after all. In the Sophie example, even with the apparatus of substitution, I still place the performance in the inferential web $I$ acknowledge, and Sophie still places it in the inferential web she acknowledges. And since, in virtue of our differing commitments, the significance we take the performance to have (and so the content we thereby implicitly or explicitly attribute to it) necessarily differs.

What the de re apparatus provides, at best, is an explanation of how each subject attaches to a performance or expression the normative status she takes it to possess, 
which surely falls short of an account of its possessing a shared significance. Crucially, note that there is no sense of the significance each person attaches to a word being suitably (or at all) responsive to the significance that others attach. Each person's understanding has no bearing on that of her interlocutors. And even if some conception of interpersonal content were available - as what is common to all the different attributions of significance made to a given utterance of an expression - it would float entirely free of subjects' attitudes, which would be utterly indifferent to it. Hence the problem of communication remains. ${ }^{21}$

Brandom seems to have lost hold on any notion of communication, mutual understanding, and so shared meaning. It might be the case that two individuals can talk about the same thing - although it is far from clear that this is to be had in advance of the notion of talking per se - but still they cannot take themselves to be saying the same thing. Thus, Brandom's appeal to de re locutions fails to provide an adequate account of semantic content.

Not only is this an unfortunate result for his IRS, it is a surprising one given Brandom's pragmatist orientation. An appeal to notions such as use or practice is typically presented as placing emphasis on the public nature of linguistic activity, as an insistence that understanding be manifest, as appropriately situating the notion of meaning in its characteristic context of communication, and more generally as dissuading us from a Cartesian conception of subjects as essentially cut off from one another in private realms. Ironically, Brandom's actual description of scorekeeping practice, and the attitudes it incorporates, enforces precisely that conception. 
So, the problem is that for Brandom there is no sense in which mutual understanding is possible at all, since there is no constant (an invariant meaning) between speakers, and so nothing to anchor communication. Given that interlocutors with different beliefs take expressions and performances to stand in different inferential contexts, there is no respect in which they can take those expressions in the same way, or treat one another's performances as possessing the same significance. The introduction of de re locutions was supposed to meet this difficulty, but the suggestion is that it fails to do so.

\section{Externalism}

Brandom might charge the above criticisms with overlooking the semantic externalism that he advocates. On his view, the content of a claim, and derivatively the meaning of the corresponding expression, is determined by objective inferential relations, that is, relations that correspond not to any perspective but to "how the world is'. Thus, there is an independent, shareable content, of which all practitioners can have firmer or looser grasps. What performances are proper or improper is a matter of how things stand in the world (MIE, 632), though of course one must be a scorekeeping practitioner to appreciate this. While this variant of externalism would perhaps solve the communication problem, it in turn introduces a number of (increasingly severe) problems. ${ }^{22}$

If semantic content or meaning consists solely in objective relations between the relevant features of the world, one loses any link between the 'co-ordinate' (MIE, 73) concepts of meaning and understanding. That is, one cannot account for the cognitive difference in co-extensive terms or, rather, the inferential relations between them. For 
example, objectively-speaking, the inferences from 'That is a creature with a heart' to 'That is a cordate', and from 'That is a creature with a heart' to 'That is a renate', are correct in just the same instances. Thus, on the account being considered here, the terms 'cordate' and 'renate' have the same meaning, or express the same content. However, they are surely understood differently; they have a different cognitive significance (shown by the fact that one could coherently take opposing psychological attitudes towards the two inferences). Since Brandom (for good reason) does not wish to divorce understanding and meaning, he cannot endorse this account. Introducing a notion such as meaning or sense to supplement that of reference is intended to account for the cognitive significance of what is said (see Frege, 1892). For Brandom to revert back to reference at the expense of such content is precisely to relinquish meaning. ${ }^{23}$

Moreover, in dropping meaning, or a fine-grained individuation of content, in favour of a coarse-grained individuation of content, one would lose a central motivation for pursuing IRS. Insofar as IRS explains the meaning of an expression, or the concept it expresses, in terms of its role in reasoning, it captures the cognitive significance of an expression and thereby avoids the familiar Frege-problems (see Lepore 1994, 193). My aim here is not to defend Fregeanism, or even IRS, but only to note that prima facie the latter is committed to the former.

In any case, Brandom cannot avail himself of the appeal to externalism so construed, since (taken literally) semantic externalism would commit him to a view according to which proprieties of inference are in force, and so contents or meanings in place, in isolation from any practice or practitioner. This is clearly antithetical to IRS. Instead, Brandom must restrict himself to the inferential role being determined by how 
practitioners take things to be. But in this case, one is back to the problem of mutual understanding and so shared meaning. ${ }^{24}$

So, it seems that Brandom's semantic externalism provides no obvious resolution of the problems associated with holism. The brand of externalism he outlines threatens to distance semantic, intensional notions from the actual activities and perspectives of linguistic practitioners. But the 'internalist' construal, according to which speakers' attitudes and resultant use of an expression alone are determinative of content, remains untenable so long as one endorses global holism.

In fact, on closer inspection, Brandom's version of IRS does not anyway appear to provide a genuine externalism. According to it, the meaning of an expression or the content it expresses is determined by how things objectively are according to the one ascribing or attributing that meaning or content. It is, then, still the case that, on Brandom's theory, meaning is determined in the first instance by the attitudes of each speaker, not by extra-linguistic reality. Indeed, this is evident from careful attention to Brandom's actual formulations. On his view, the correct use of an expression (and thereby its meaning) is not determined, as he often suggests, by objective matters 'transcending the attitudes of practitioners' (AR, 198), but rather by 'how things objectively... are taken to be' (MIE, 498, my underlining; cf. AR, 183). Hence, this aspect of Brandom's IRS does not really provide a determinate of meaning that is unaffected by differences in inferential profiles, and so does not circumvent the communication problem. 


\section{Models of communication}

It has been put to me by those sympathetic to Brandom on this issue that the above criticisms take for granted a conception of successful communication that Brandom rejects. Call it 'the conveyance model'. According to that model, successful communication involves 'sharing a relation to one and the same thing' (MIE, 479), 'the joint possession of some common thing' (MIE, 485). On this account, there is an entity - a meaning - that is transported from a speaker to an audience via a suitable vehicle (the tokening of an expression). Now, Brandom might grant that his version of IRS, and the ability made explicit by de re ascriptions that it incorporates, is incompatible with the conveyance model but insist that such a model is in any event to be abandoned.

Importantly, no grounds have as yet been offered for agreeing that the conveyance model, which Brandom admits is 'natural' and 'commsensical' (MIE, 479), is nevertheless objectionable. And such grounds surely cannot be simply that it does not accord with Brandom's favoured theory of meaning. Hence, one might think that if the two conflict, so much the worse for his version of IRS. However, irrespective of the status of the conveyance model, I hope to show that the appeal to de re ascription fails to explain how communication is possible, even granting Brandom's own conception of communication.

Notably, Brandom wants to hold on to the notions of 'understanding, grasping a meaning - the cognitive uptake of communication' (MIE, 485). Indeed, on his view, one can 'strictly be said to understand what another says', and contents can 'genuinely be shared' (MIE, 590). ${ }^{25} \mathrm{He}$ is confident, however, that such phenomena are captured 
by an alternative to the conveyance model. Call it 'the cooperative model'. According to it, one should think of communication 'in terms of cooperating in a joint activity' (MIE, 479):

The paradigm of communication as joint possession of some common thing is relinquished in favor of - or modified in the direction of - a paradigm of communication as a kind of cooperation in practice. (MIE, 485)

In light of these remarks, and drawing upon the materials assembled in previous sections, I shall assess the extent to which Brandom's theory is acceptable by the lights of the cooperative model. Before doing so, however, I shall consider how we are to understand communication or mutual understanding according to it.

Importantly, it ought to be possible to outline the conveyance model independently of the details and terms of Brandom's specific theory of meaning. This is necessary so that one can judge, first, whether the former is an independently attractive picture of communication and, second, whether Brandom's own account does justice to it. Unfortunately, Brandom offers relatively little by way of such an autonomous characterisation of the model of communication he prefers, and for the most part we are left to understand it only according to the terms of this particular version of IRS. This makes it difficult to assess both the cooperative model's own merits and the extent to which it differs from the conveyance model. As far as I can tell, the little Brandom offers is the following analogy:

The participants [in conversation] do not need all to be doing the same thing (sharing) in a narrow sense in order to be engaged in a joint enterprise, and in that broader sense to be doing the same thing (sharing) [...] Conversational partners should not be pictured as marching in step, like soldiers on parade, but more as ballroom dancers, 
each making different movements $[\ldots]$ and thereby sharing a dance that is constituted precisely by the coordination of their individually different movements. $(2000 \mathrm{~b}, 363)$ Without placing too much weight on a single simile, one can ask what picture of communication it suggests. Clearly, Brandom wishes to oppose the idea that successful communication requires that speakers perform and respond to performances in just the same way. Furthermore, the idea is surely not that there is some single thing - akin to a tune or rhythm in dance - with which both parties should be acquainted. This interpretation bears too much resemblance to the conveyance model. Presumably, the idea is rather that, while the participants' moves (utterances, in the case of conversation) might be radically different, successful conversation requires that those moves be suitably responsive to one's other moves and those of one's partners, that the participants' performances be coordinated. Thus, in the first instance, what those party to the conversation share is not a meaning as such but a mutual activity, from which the meaning subsequently emerges or in which it is thereby apparent.

While somewhat speculative, this interpretation accords with Brandom's own description of communication, given in the specific terms of his theory. On his account, successful communication requires not that speakers attribute 'the same significance' to a performance; it is rather a matter of 'coordinating social perspectives by keeping deontic score according to common practices' (MIE, 479). And, as we have seen, this 'consists in auditors being able to move between their own doxastic perspective and that of the speaker in just the way expressed in de re ascriptions' (MIE, 513). This in turn is supposedly made possible in the following way: 
Anaphoric connections among tokenings that are utterances by different interlocutors provide a way of mapping their different repertoires of substitutional commitments onto one another. (MIE, 474-5)

Considered apart from the actual details and terms of Brandom's version of IRS, the cooperative model of communication appears unobjectionable. Of course, such a schematic picture needs to be fleshed out considerably but there is nothing obviously amiss in the idea that mutual understanding requires participants in a discussion to be suitably sensitive to one another's performances, that it involves a kind of negotiation between the moves one considers proper and those that one's partners consider proper and thus demands appropriate degrees of give and take. So, without taking a stand on the extent to which this picture competes with the conveyance model, it is time to ask to what extent Brandom's account accords with it. I shall suggest that the objections made in the preceding sections are as effective by the lights of the cooperative model as those of its supposed rival.

On the favoured model, successful communication requires practitioners to cooperate in a joint activity (or common practice) by coordinating their commitments and so performances. However, as argued above, the 'interpretive' ability possessed by a practitioner is only an ability to attach to a performance the significance she takes it to have, to connect it with and evaluate it according to her own repertoire of doxastic commitments. But surely this falls far short of an ability to cooperate by coordinating one's commitments and moves with those of one's interlocutors. If the arguments of the preceding sections are on target, practitioners are simply indifferent to one another's performances. They are not, of course, insensitive to the brute fact that moves are being made, but cooperation (i.e. collaboration, working together) further 
requires sensitivity to one's interlocutors' attitudes towards those moves (if not harmony with them). And the ability made explicit in de re ascriptions does not enable this. The problem is not that nothing is exchanged, as the conveyance model requires, but that participants are not suitably responsive to one another, as the cooperative model requires. And since there is no genuine cooperation, there is no practice that they can properly be said to be jointly participating in; they have nothing of relevance in common (beyond the sheer fact that both are undertaking various performances). Although there is activity of which each is a part, each is going her own way, so to speak.

Brandom's appeal to de re ascription fails, therefore, to solve the communication problem according to both models here considered. The conveyance model involves practitioners adopting the same attitude towards a performance. In contrast, the cooperative model allows for different attitudes, so long as they are responsive to those of others. Unfortunately, the ability made explicit by de re ascription involves neither. To put the problem picturesquely, and adapting Brandom's own image, it is not that the dancers are making different movements, but that they are not dancing together; they are dancing alongside each other but not with each other.

To make a more general point in closing, it is not at all clear that one commits oneself to any particular model of communication simply in virtue of holding that a theory of meaning must allow for such seeming platitudes as that it is possible for two speakers to understand an utterance in the same way, to say the same thing, and not always to talk past one another. Both the cooperative model and the conveyance model are 
supposed to capture these platitudes and, I argued, Brandom's version of IRS is therefore incompatible with them.

\section{$7 \quad$ Analyticity}

A proponent of IRS needs a story that avoids severing the link between meaning and understanding, but without relativising the former to individual understanding to such an extent that shared meaning (and hence communication) is impossible. My suggestion is that the holism be moderated. If an IRS of the kind Brandom outlines is to succeed, certain inferential relations must be privileged as determinative of the meaning or content of the relevant expression or utterance, and others treated as nondeterminative. That is, some inferences must be viewed as analytic. This would provide something constant between contexts, an invariant meaning that all practitioners could (in principle) grasp, irrespective of their different beliefs.

Note that, in examining Brandom's version of IRS, a pattern has emerged.

Repeatedly, his appeal to the apparatus of de re ascription has not provided a genuine account of meaning or content that different speakers can grasp irrespective of differences in background beliefs. At best, the analysis of de re ascription appears to provide an explanation of how an ascriber can interpret another's claim according to her own perspective and hence from outside her target's, whereas what is required is an explanation of how a shared perspective on a person's words is possible.

Distinguishing certain inferential transitions as analytic provides precisely that.

No doubt many philosophers would take the need to introduce an analytic/synthetic distinction to be reason to reject IRS altogether. As stated from the outset, while I am confident that a principled version of such a distinction can be drawn, I shall not argue 
for that here. What matters for present purposes is that Brandom's novel alternative to that strategy is unsuccessful and so, if one is sympathetic to IRS, a reassessment of the arguments against the notion of analyticity is called for. ${ }^{26}$

\section{References}

Beaney, M., ed. 1997. The Frege Reader. Oxford: Blackwell.

Block, N. 1995. “An Argument for Holism.” Proceedings of the Aristotelian Society 95: 151-69.

Boghossian, P. 1993. "Does an Inferential Role Semantics Rest Upon a Mistake?" Mind and Language 8: 27-40.

--- 1994. "Inferential Role Semantics and the Analytic/Synthetic Distinction." Philosophical Studies 73: 109-122.

--- 1997. “Analyticity.” In A Companion to the Philosophy of Language, ed. B. Hale and C. Wright. Oxford: Blackwell.

--- 2003. “Epistemic Analyticity: A Defence.” Grazer Philosophische Studien 66: 1535.

Brandom, R. 1994. Making it Explicit: Reasoning, Representing, and Discursive Commitment. Cambridge, Massachusetts: Harvard University Press.

--- 2000a. Articulating Reasons: An Introduction to Inferentialism. Cambridge, Massachusetts: Harvard University Press.

--- 2000b. "Facts, Norms, and Normative Facts: Reply to Habermas." European Journal of Philosophy 8: 356-374.

Fodor, J. and Lepore, E. 1991. "Why Meaning (Probably) isn’t Conceptual Role.” Mind and Language 6: 329-43.

--- 1992. Holism. Oxford: Blackwell. 
--- 2001. 'Brandom's Burdens: Compositionality and Inferentialism.' Philosophy and Phenomenological Research 68: 465-482.

Frege, G. 1892. “On Sinn and Bedeutung.” Reprinted in Beaney, 1997.

Glock, H-J. 2003. Quine and Davidson on Thought, Language, and Reality. Cambridge: Cambridge University Press.

Grice, P. 1989. Studies in the Way of Words. Cambridge, Massachusetts: Harvard University Press.

Grice, P. and Strawson, P. 1956. "In Defense of Dogma.” Reprinted in Grice, 1989.

Harman, G. 1993. "Meaning Holism Defended.” Grazer Philosophische Studien 46: $163-71$.

Hattiangadi, A. 2003. "Making it Implicit: Brandom on Rule Following.” Philosophy and Phenomenological Research 66: 419-431.

Horwich, P. 1992. "Quine versus Chomsky on the Analytic/Synthetic Distinction.” Proceedings of the Aristotelian Society 92: 95-108.

--- 1998. Meaning. Oxford: Oxford University Press.

--- 2005. Reflections on Meaning. Oxford: Oxford University Press.

Laurier, D. 2005. “Pragmatics, Pittsburgh Style.” Pragmatics and Cognition 13: 141160.

Lepore, E. 1994. “Conceptual Role Semantics.” In A Companion to the Philosophy of Mind, ed. S. Guttenplan. Oxford: Blackwell.

Lycan, W. G. 2000. Philosophy of Language. London: Routledge.

McCullagh, M. 2005. “Motivating Inferentialism.” Southwest Philosophy Review 21: $77-84$

McDowell, J. 2005. "Motivating Inferentialism.” Pragmatics and Cognition 13: 121140. 
Peacocke, C. 1992. A Study of Concepts. Cambridge, Massachusetts: MIT Press.

--- 1997. "Holism." In A Companion to the Philosophy of Language, ed. B. Hale and C. Wright. Oxford: Blackwell.

Putnam, H. 1991. Representation and Reality. Cambridge, Massachusetts: MIT Press. Quine, W. V. O. 1951. “Two Dogmas of Empiricism.” Reprinted in Quine 1980.

--- 1980. From a Logical Point of View, $2^{\text {nd }}$ ed. Cambridge, Massachusetts: Harvard University Press.

Whiting, D. 2006a. “Conceptual Role Semantics.” In The Internet Encyclopedia of Philosophy, ed. J. Fieser and B. Dowden. http://www.iep.utm.edu/

--- 2006b. "Between Primitivism and Naturalism: Brandom's Theory of Meaning" Acta Analytica 21: 3-22.

--- 2007. "Fregean Sense and Anti-Individualism.” Philosophical Books 48: 233-240. 


\section{Notes}

${ }^{1}$ For arguments in support of IRS, see Brandom, 1994, chs. 1-3; Horwich, 1998, chs. 1-2; and Whiting, 2006a. For a critical response to Brandom's arguments, see McCullagh, 2005; McDowell, 2005. Throughout this paper, I shall use the following abbreviations for Brandom's texts: MIE - Making it Explicit; AR - Articulating Reasons.

${ }^{2}$ Some proponents of IRS might object to marking the distinction with the term 'analytic', since it is associated with putatively suspect notions such as true in virtue of meaning or knowable a priori. However, I intend it only as a label for the privileged meaning-constituting inferential transitions, and do not assume in advance that it carries any other commitments.

${ }^{3}$ There is a substantial amount of interdependency among the many issues Brandom investigates. Specifically, Brandom's explanations of the possibility of communication, de re and de dicto ascriptions, the objectivity of semantic norms, the possession of empirical content, semantic externalism, the nature of representation, and his dissolution of Kripkean meaning-scepticism all occur simultaneously! Nevertheless, for the purposes of this paper I shall single out certain topics for independent discussion, even if full assessment of Brandom's views eventually requires attending to the others. For discussion of remaining topics, see Laurier, 2005 and Hattiangadi, 2003. Laurier questions whether the appeal to de re ascription affords an explanation of the objectivity of semantic norms, while Hattiangadi disputes Brandom's claim to have avoided the familiar Kripkean rule-following problems.

${ }^{4}$ For a start, see Boghossian, 1997; 2003; Glock, 2003, ch. 3; Grice and Strawson, 1956; Horwich, 1998. Interestingly, Brandom holds that Quine's critique of 
analyticity is 'hardly decisive' (MIE, 484). For a critical discussion of holism in general, see Peacocke, 1997.

${ }^{5}$ Brandom views the notion of linguistic meaning as derivative from that of propositional content: 'it is not tokens but tokenings that are in the first instance considered as contentful. Sign-designs, the linguistic vehicles of content, are meaningful only at one remove, in virtue of their involvement in linguistic practices that express intentional states and attitudes' (MIE, 664m10).

${ }^{6} \mathrm{Cf}$. '[T] he inferential proprieties of inference that from the point of view of semantic theory are treated as primitive can be explained in the pragmatic theory as implicit in discursive practice.' (MIE, 133; cf. 190) Also: 'semantic primitives are themselves explained in terms of a prior pragmatics, which in turn appeals to normative primitives' (MIE, 681n6). For critical discussion of this reductionist aspect of Brandom's account, see Whiting, $2006 \mathrm{~b}$.

${ }^{7} \mathrm{Cf}$. 'Content is understood in terms of proprieties of inferences, and those are understood in terms of the norm-instituting attitudes of taking or treating moves as appropriate or inappropriate in practice [...] In this way, a suitable pragmatic theory can ground an inferential semantic theory.' (MIE, 134)

${ }^{8} \mathrm{Cf}$. ' $[\mathrm{H}]$ olistic conceptual role approaches to semantics potentially face problems concerning $[\ldots]$ the possibility of communication between individuals who endorse different claims and inferences.' (AR, 29) Also: 'an inferential conception of concepts raises prima facie difficulties for understanding what is involved in communication' (MIE, 633).

${ }^{9} \mathrm{Cf}$. 'The underlying point is that what a given endorsement of a claim commits one to, is entitled by, and is incompatible with depends on what else one is committed to, 
on what collateral information is available as auxiliary hypotheses for the inferences in question.' (MIE, 477; cf. 590-1)

${ }^{10}$ It might be thought that this problem could be avoided if one recognises that inferential profiles are communal. So long as different interlocutors are suitably related (say, deferentially) then their claims possess the same content. First, however, even if this suggestion resolves the communication issue, the associated problem of constancy would remain, because the communal profile would constantly change. Second, the communication problem only resurfaces as that of how groups communicate.

${ }^{11}$ Fodor and Lepore mention that Brandom's IRS faces the communication problem (2001, 469n5) but wrongly claim that he has 'little to say' about it. Although they critically discuss his views on de re ascription (477-8), Fodor and Lepore overlook Brandom's linking of the two issues.

12 This problem is aggravated by Brandom's endorsement of a paratactic analysis of ascriptional locutions. For example, Brandom parses 'Galileo said that the earth moves' as follows (MIE, 538):

Galileo said (something that in his mouth then committed him to what an assertional utterance of this in my mouth now would commit me to): The earth moves.

This makes vivid the respect in which making an ascription requires that the ascriber is able to undertake the same commitments as her target. And it seems that, given their differing perspectives, this is never the case. Nothing 'in my mouth' could have the same significance as something in Galileo's, if global holism is true.

${ }^{13}$ This needs to be qualified as involving suitable shifts of indexical expressions and language (for cases where the target does not speak the language of the ascription) (AR, 218n8; MIE, 544). 
${ }^{14} \mathrm{Cf}$. 'Since the same words in the ascriber's mouth often do not express the same claim that they would in the mouth of the one to whom a claim is ascribed, the content specifications must take account of the difference in discursive perspective between the ascriber and the target of the ascription. Claims must often be differently expressed from the two points of view.' (MIE, 589-90)

${ }^{15} \mathrm{Cf}$. 'The difference is just whether the expressive commitment, to a particular form of words being a way of expressing the commitment in question, is attributed along with the doxastic commitment being ascribed or undertaken along with the ascriptional commitment itself.' (MIE, 545)

${ }^{16} \mathrm{Cf}$. 'Unless one has the substitutional interpretive capacity, which is expressed explicitly in de re specifications of the contents of ascribed commitments, one would not be able to understand what others are saying.' (MIE, 513)

${ }^{17}$ Nothing that follows is intended as an objection to Brandom's account of the role of ascriptional locutions as such, which strikes me as very much along the right lines, but only to whether an appeal to that role can address the problems holism raises for IRS. ${ }^{18}$ One might worry that the objections that follow rest upon a suspect view of communication. In $\S 6$, I shall address this concern at length in the light of the amassed criticisms of Brandom's account.

${ }^{19}$ One might think that a wholly de re ascription could be parsed in the following way:

(5') Sophie claims, of the claim that the vehicle parked in the garage ran over the cat, that it is a fact.

First, however, one might note in passing an oddity in the suggestion that understanding another's utterance requires implicit or explicit mastery of semantic notions such as claim or fact. Second, and crucially, Brandom views facts as true 
claims, and so the locution 'is a fact' as equivalent to 'is true' (MIE, $327 \mathrm{ff}$ ).

Moreover, he offers a prosententialist account, according to which sentences of the form ' $p$ is true' (and likewise ' $p$ is a fact') are prosentences whose significance or content is determined by a class of admissible sentential substituends, perhaps the tokened sentence the prosentence contains (MIE, 301ff). Hence, the significance of the outstanding de dicto component of (5'), namely 'it is a fact', depends on which substitutional commitments one takes to be correct, namely whichever one takes to govern 'The vehicle parked in the garage ran over the cat'. Insofar as ascriber and target will differ over which such commitments are appropriate, it remains the case that their understanding of the claim will differ. (Should this response not prove adequate, the objections of the preceding and subsequent sub-sections remain.) ${ }^{20}$ For Brandom's analysis of demonstratives, with which this objection is consonant, see MIE, 459ff.

${ }^{21}$ One might think that communication or shared understanding only requires that a term has the same meaning for two people, whether or not both take it to have that meaning. Note, however, that in the first instance Brandom explains the inferential significance of a claim in terms of what practitioners take it to be, and it is by appeal to de re ascription that he accounts for its objective significance. Although examining in detail this aspect of Brandom's theory is beyond the scope of this paper (see Laurier, 2005), the problem, again, is that the ability made explicit by de re ascription is at best an ability to ascribe to a claim the objective significance a speaker takes it to have, not the objective significance it does have (see $§ 5$ ).

Aside from the details of Brandom's IRS, it seems counterintuitive to hold that mutual understanding involves no responsiveness to one's interlocutors' attitudes. Moreover, insofar as the above account distances meaning from practitioners' 
attitudes, it undermines a central motivation for IRS, which promises precisely to account for the cognitive significance of what terms express (see, again, §5). Finally, on this conception the communication problem does not seem to arise and the appeal to de re ascription is otiose. That speakers differ in the significance they take a claim to have, given their different beliefs, does not show that they do not communicate, so long as that claim has a certain significance for both (in virtue perhaps of their combined doxastic profiles, or how things stand in the world). This paper takes for granted the communication problem and aims to address the question of whether appealing to de re ascription can solve it. This seems legitimate, even if the issue does not arise according to the alternative model of communication sketched above. I shall return to discuss models of communication in $\S 6$.

${ }^{22}$ What follows is not intended as an argument against externalism per se, but only Brandom's particular variant of it and its efficacy in resolving the communication issue.

${ }^{23}$ The extent to which externalism and Fregeanism, which involves a fine-grained individuation of content, are compatible is a thorny issue. For some discussion, see Whiting, 2007.

${ }^{24}$ Lepore (1994, 197-8), Lycan $(2000,93)$ and Putnam (1991, 46ff) all note a prima facie incompatibility between IRS - according to which meaning is had in virtue of word-word relations - and externalism - according to which meaning is had in virtue of word-world relations.

${ }^{25}$ On Brandom's account, it is supposed to be possible for speakers to 'use others' judgements as reasons', that is, 'for the claims undertaken by one interlocutor to become available to others (who attribute them) as premises and conclusions' (MIE, 474-5). 
${ }^{26}$ I am grateful to the Arts and Humanities Research Council for funding that made it possible to write this paper. Thanks to audiences at the Australian National University (RSSS), the University of Oxford, and the University of Reading for comments on this material, and to Charlie Pelling, Hanjo Glock, Andrew Jorgensen, Tim Williamson and anonymous referees for invaluable feedback on earlier versions. 